\title{
COGNICIÓN, EMOCIÓNY
}

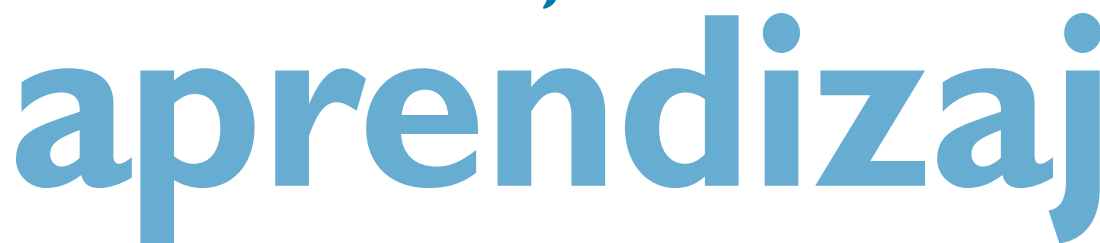

\section{Carme Timoneda Gallart}

Directora de la Fundación Carme Vidal Xifre de Neuropsicopedagogia Profesora titular del Departamento de Pedagogía de la Universidad de Gerona carme.timoneda@udg.edu

.

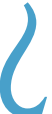

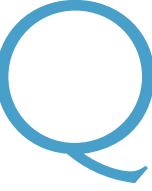

ué significa aprender? ¿Cómo aprendemos? Si partimos de la etimología de la palabra "aprender", nos damos cuenta de que proviene del concepto de "apoderarse". Realmente aprendemos algo cuando nos apoderamos de ello. La neurociencia nos confirma la extrema plasticidad del cerebro. Según sus postulados, el cerebro se construye a sí mismo. Esto significa que para que realmente aprendamos algo, debe de producirse un "cambio" en el cerebro, es decir, en las conexiones que configuran las múltiples redes neuronales.

\section{- Para que} realmente aprendamos algo, debe de producirse un "cambio" en el cerebro, es decir, en las conexiones que configuran las múltiples redes neuronales.

\section{NeURociencia Y APRENDIZAJE}

Esta concepción del aprendizaje derivada de las aportaciones de neurociencia nos indica un cambio de mirada, un nuevo paradigma que, a mi modesto entender, revoluciona el mundo educativo en cuanto a ubicar lo aprendido no en el "exterior" (resultado) sino en el "interior" (proceso mental). Ilustrémoslo con un ejemplo. Imaginemos que un profesor está con sus alumnos en el aula explicándoles los números enteros. Cuando termina su explicación escribe un ejercicio en la pizarra. Los alumnos lo resuelven en su cuaderno. El profesor observa el resultado, es decir, lo que cada alumno ha escrito, pero, cabe preguntarnos: ¿este resultado nos indica que el alumno se ha apoderado del concepto de número entero y será competente en el dominio de este contenido en el futuro? La respuesta es "no necesariamente". La experiencia nos ha mostrado en multitud de ocasiones que cuando se presentan situaciones cotidianas que se convierten en el espejo de si el cerebro se ha apoderado o no de un concepto, observamos que no ha sido así. Me viene a la memoria el caso de un señor que me contó que quería comprar un terreno para construir una casa. Le dieron unos planos con las medidas del perímetro. Él fue en busca de su hija que cursaba 4. ${ }^{\circ}$ de ESO y le dijo si podía ayudarle a calcular cuántos

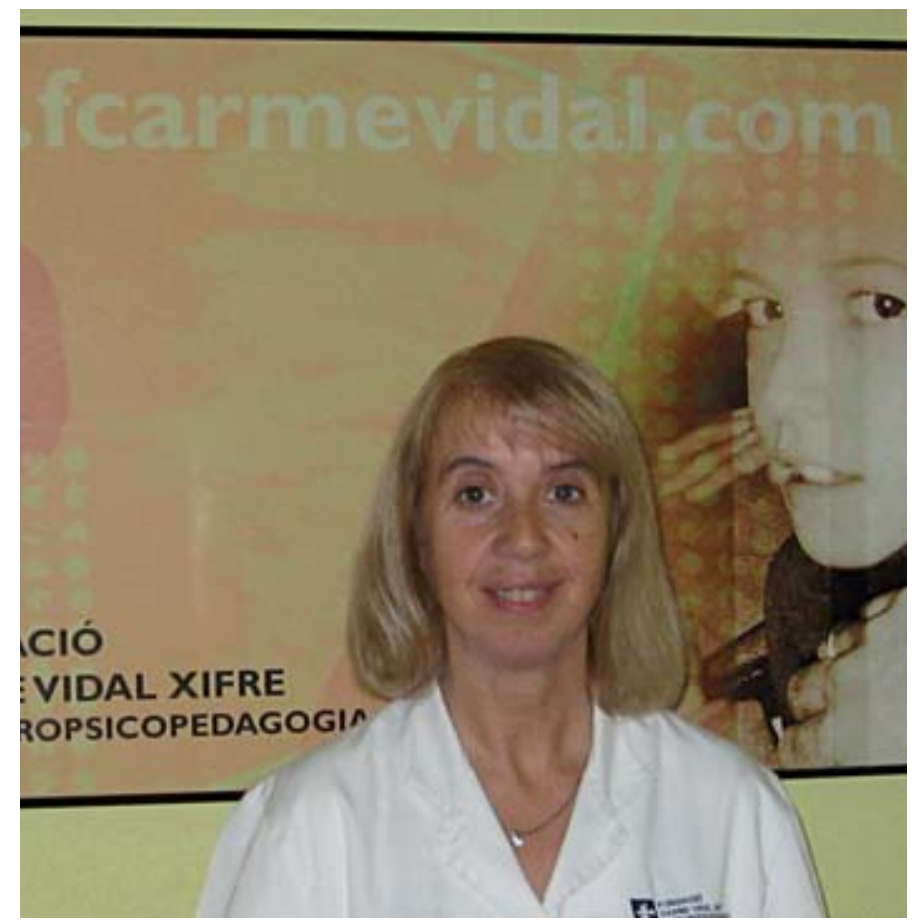

Carme Timoneda Gallart. 
metros cuadrados exactos tenía la parcela. La hija, después de mirar el plano detenidamente, le contestó: "Papá, no es posible calcular el área porque tiene una forma muy rara”. El buen hombre se preguntaba de qué le servirían a su hija los excelentes que sacaba en matemáticas.

\section{Procesos cognitivos Y APRENDIZAJE}

A partir de las investigaciones del Dr. Das se han establecido unas bases sólidas y fundamentadas que han derivado en la teoría PASS de la Inteligencia. Esta concepción dinámica del acto mental basada en los estudios de Lúria describe el funcionamiento del cerebro consciente como la interacción de cuatro procesos cognitivos: plani-

ficación, atención, simultáneo y secuencial. Fijémonos que la letra inicial de cada uno de estos procesos da nombre a la teoría PASS.

Cuando un estímulo (pregunta oral, texto escrito, etcétera) es captado por los sentidos, es el proceso de atención el encargado de introducirlo al cerebro. Es como si de una linterna se tratara. Enfocamos dónde se genera el estímulo y mantenemos la linterna enfocada el tiempo necesario para que entre esta información. Este proceso está en estrecha conexión con la planificación la cual puede ser comparada con un director de orquesta. Es decir, es el director de orquesta quien da órdenes a la linterna para que enfoque y para que se mantenga enfocada el tiempo necesario hasta que éste sepa qué le están pidiendo. Este proceso de planificación radica en los lóbulos prefrontales, y su buen funcionamiento es básico y fundamental para que se produzca un aprendizaje cualquiera.

Una vez este director de orquesta sabe o entiende qué se le pide, formulando así un objetivo, se pone en contacto con los dos procesos relacionados con las estrategias; es decir, el simultáneo y el secuencial. El primero de ellos, el simultáneo, actúa como si de una televisión se tratara. Los lóbulos occipitales y parietales son su correlato neurológico. Gracias al proceso simultáneo podemos operar mentalmente con imágenes, dar significado a los conceptos y establecer relaciones. Si ahora pensáramos en un ratón paseando orgulloso sentado encima de un elefante, es muy probable que nos imagináramos la escena y activaríamos nuestro proceso simultáneo. También activaríamos este mismo proceso si nos preguntaran por ejemplo: ¿en qué se parecen un perro y un cocodrilo?, ya que nuestra actividad mental se centraría en relacionar ambos significados.
Cuando el objetivo es aprender, por ejemplo, cómo se pronuncia la palabra inglesa write, nuestro director de orquesta necesita poner en marcha el proceso secuencial. Fijémonos que es una tremenda arbitrariedad la que caracteriza esta tarea mental. Siguiendo con los paralelismos metafóricos podríamos comparar este proceso secuencial con un loro. Cuando preguntamos a un niño qué hacen los loros, nos responden: "Hablan sin saber lo que dicen". Pues esta es la esencia de este proceso que no entiende de significados ni de relaciones, sino de convencionalismos y de arbitrariedad. La base neurológica que lo sustenta es el lóbulo temporal y una pequeña parte del prefrontal. El primer aprendizaje del que un cerebro necesita apoderarse basado en gran medida en el proceso secuencial es el lenguaje oral y más adelante, el lenguaje escrito. Sabemos ahora que la disfunción, que el término "dislexia" intentaba sistematizar, es debida a un disfuncionamiento y a un problema genético madurativo de este proceso secuencial. Démonos cuenta de la importancia de entender un resultado (sintomatología de dislexia) desde la perspectiva de los procesos cognitivos pues la intervención irá encaminada a "provocar cambios en los engranajes mentales del cerebro" y no a modificar el resultado (escritura, lectura, etcétera).

\section{Evaluación de los PROCESOS COGNITIVOS}

La batería Das y Naglieri-Cognitive Assesment System (DN-CAS) cuya versión original en inglés ha sido traducida a múltiples lenguas se convierte en una herramienta francamente útil a la hora de valorar los procesos cognitivos, ya que nos aporta información de cómo aquella persona usa sus engranajes mentales en aquel momento de su vida y según su situación personal. La diferencia más destacable entre esta batería diagnóstica y los test de inteligencia tradicionales 
radica en que nos descubre aquello que de otro modo no podríamos observar ya que focaliza en cómo y en qué medida la persona está usando sus procesos cognitivos PASS. Consecuentemente, en el caso de que se constate un bajo rendimiento o un problema de aprendizaje, el DN-CAS nos permite formular una hipótesis diagnóstica con un alto grado de fiabilidad basada en si la problemática tiene un origen neurocognitivo y/o neuroemocional.

\section{es necesario intervenir e incidir en los mecanismos cerebrales que originan los procesos, sean cognitivos o emocionales, para conseguir que los aprendizajes sean eficaces}

\section{Procesos emocionales y APRENDizaje}

Los estudios de Ledoux sobre el procesamiento del dolor han constituido una gran aportación para entender el componente emocional presente en todo proceso de aprendizaje. Resumiendo, Ledoux nos dice que cuando un estímulo es percibido por nuestro cerebro, antes de que nuestro director de orquesta (proceso cognitivo de planificación) se percate de él, ya se han puesto en funcionamiento las estructuras relacionadas con el procesamiento emocional, es decir, el sistema límbico y, en concreto, la amígdala. Esta estructura tiene como misión fundamental cap- tar si el estímulo en cuestión "es potencialmente peligroso o doloroso para la persona”. En caso afirmativo, la amígdala desencadena una conducta de protección que podemos tildar de provocativa, exagerada e incongruente. Lo que es llamativo es que se produce de manera automática e inconsciente y siempre tiene lugar antes de que se ponga en marcha el funcionamiento cognitivo pertinente; consecuentemente, se deriva de ello lo que denominamos bloqueo emocional. Pongamos un ejemplo: Jaime está en clase. De repente, el profesor le indica que salga a la pizarra para solucionar un problema. Jaime nota como si una ola de calor le recorriera todo su cuerpo, el corazón le late muy deprisa, se queda como paralizado en la silla... Fijémonos, el hecho de salir a la pizarra es percibido por la amígdala de Jaime como un estímulo doloroso o peligroso y, por lo tanto, desencadena en él una respuesta emocional con la finalidad de defenderle del supuesto peligro. Jaime, conscientemente, no puede impedir que esta respuesta ocurra; al contrario, cuanto más se esfuerce y se obligue a estar tranquilo, más va a notar esta respuesta emocional. ¿Cuántas veces hemos visto ejemplos similares en el contexto familiar y escolar?

Las expresiones verbales o corporales del tipo, "no podré”, "no soy capaz", "soy malo en...” pueden constituir una evidencia de que se desencadena un proceso emocional previo al cognitivo que va a dificultarlo e incluso a impedirlo. Es decir, aunque podamos evaluar unos procesos cognitivos altos mediante el DN-CAS, esto no significa que la persona pueda usarlos libremente si está bajo el influjo de un procesamiento emocional doloroso.

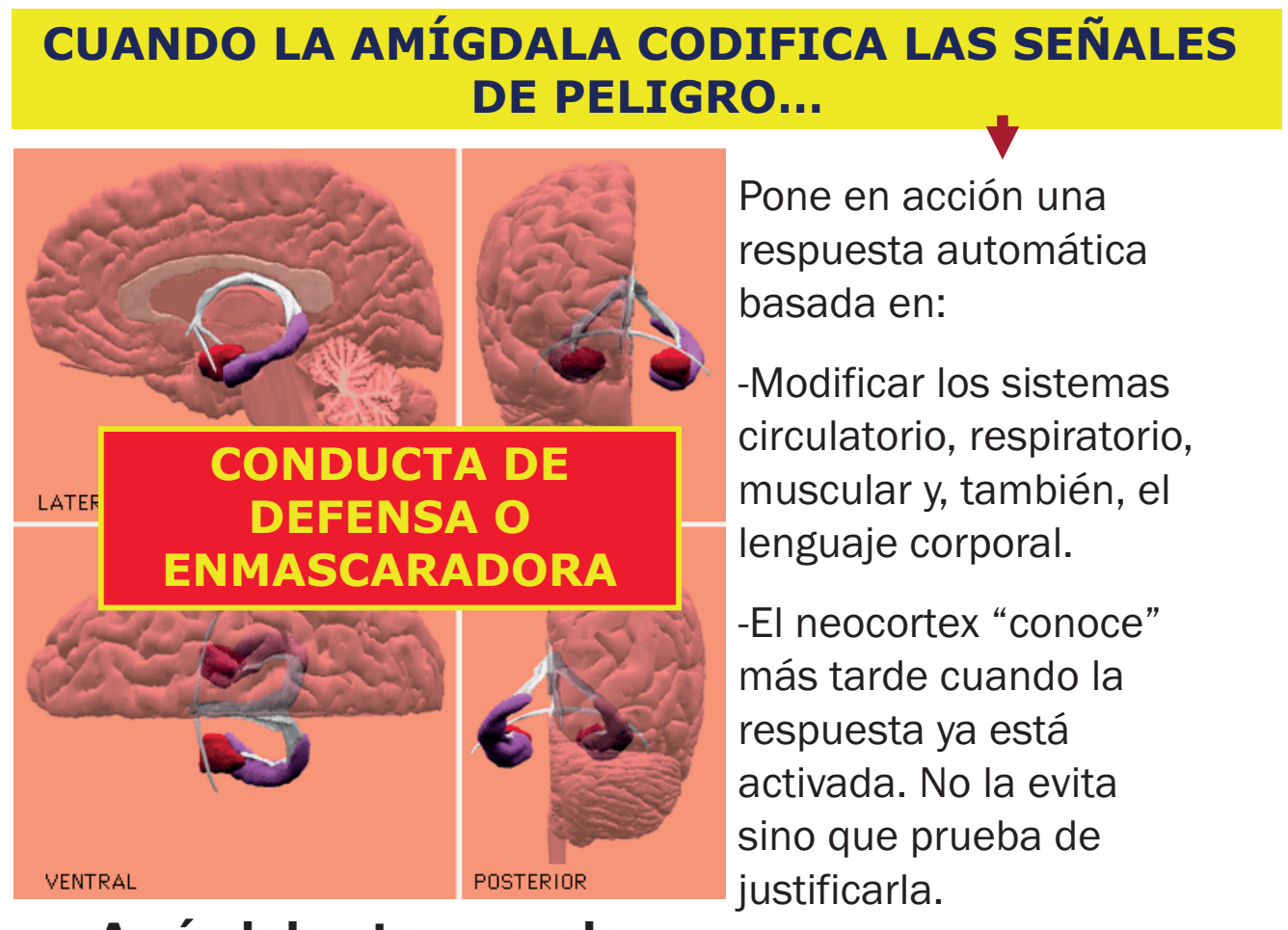

Amígdalas temporales 
Ledoux también nos ha aportado cómo se configura la sensibilidad emocional de la amígdala. Es como si se tratara de un almacén de memoria emocional. No hay experiencia vivida que no conlleve un sentir emocional. Si esta sensibilidad es muy negativa queda almacenada en la amígdala y va a convertirse en una señal de alerta en el futuro. Recuerdo el caso de Marta, una niña de dos años que siempre que había salido a la calle lo había hecho en brazos de sus padres. Cuando asistió a la escuela infantil se negaba a cruzar la calle cuando se lo requería la educadora; alzaba las manos y pedía a gritos y llorando desconsoladamente que la cogieran en brazos. Su abuela contó que un hermano mayor de la niña había fallecido en un accidente cuando cruzaba la calle después de soltarse de la mano de su padre. Este hecho marcó tanto la memoria emocional del padre y de la madre que ambos desencadenaron una conducta de protección: llevarían siempre a Marta en brazos. Pero, a su vez, Marta percibió que cruzar la calle era peligroso si no era en brazos de un adulto $y$ es por ello que, inconsciente $y$ automáticamente desencadenaba la conducta defensiva de llorar y requerir a la educadora para que la llevara en brazos; estaríamos hablando de un bloqueo emocional; aunque la profesional insistiera dando razones e intentando convencer a Marta de que no hay peligro alguno, no va a conseguirlo nunca. La niña va a necesitar nuevas experiencias almacenando sensibilidad de signo contrario para que cambie la conducta. Vemos como cognición y emoción forman un todo pero que los mecanismos cerebrales que las generan son diferentes.

\section{las conductas disruptivas,} provocativas e inadaptadas que tienen lugar en el contexto escolar en tantas ocasiones, deben de ser consideradas como comportamientos
emocionalmente inmaduros y, sobre todo, involuntarios

\section{IMPLICACIONES PARA LA ORIENTACIÓN EDUCATIVA Y LA TAREA DOCENTE}

Todo lo explicado hasta ahora tiene una gran repercusión en la metodología docente y en la orientación psicopedagógica.

En primer lugar, la necesidad de intervenir e incidir en los mecanismos cerebrales que originan los procesos, sean cognitivos o emocionales, para conseguir que los aprendizajes sean eficaces.
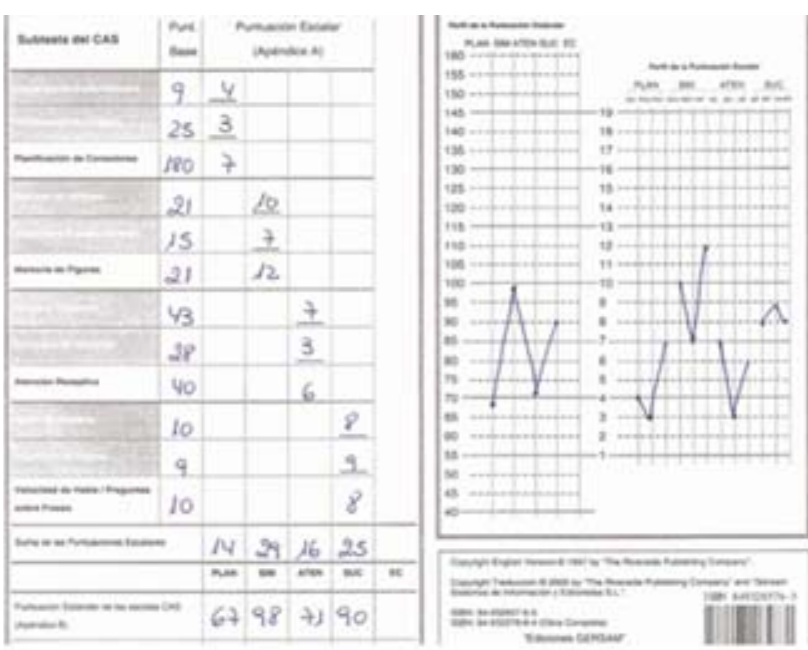

Ejemplo perfil DN-CAS: David, 10. Dificultades de aprendizaje, explicación emocional.

En segundo lugar, la importancia de entender las conductas disruptivas, provocativas e inadaptadas que tienen lugar en el contexto escolar en tantas ocasiones, como comportamientos emocionalmente inmaduros $y$, sobretodo, involuntarios. Soy consciente de la extrañeza que puede generar esta afirmación, pues en repetidas situaciones problemáticas como agresiones verbales o físicas, apatía extrema, mentiras, desorganización general, etcétera tenemos tendencia a razonar y a aplicar lo que nuestra lógica racional nos dicta (si quisiera podría no mentir, no pegar, o insultar, etcétera). Pero la neurociencia nos dice que nuestro cerebro no funciona así, sino que son conductas que, aunque diferentes en su forma, comparten un origen emocional e inconsciente. Sólo actuando en este origen ayudaremos a la persona a sentirse más segura de sí misma, lo que implicará, sentir menos peligro y, por lo tanto, las conductas problemáticas que manifestaba se desvanecerán. Para ello, hará falta conectar con sus procesos emocionales mediante técnicas de comunicación indirecta, de entre las cuales, la metáfora es la estrella.

La comunicación metafórica conlleva un componente emocional y, con ello, vamos a activar los procesos emocionales buscando que la persona pueda apoderarse de un cambio en la polaridad de su sensibilidad. Vamos a ilustrarlo con otro ejemplo. Dani, un niño de ocho años, presentaba dificultades de lectura y escritura. EI DN-CAS evidenció un proceso secuencial en la segunda desviación estándar por debajo de la media por lo que iniciamos una intervención psicopedagógica intentando que el cerebro de Dani creara nuevas conexiones a través de su proceso simultáneo (con resultado por encima de la media) con el fin de apoderarse de la lectoescritura. En una de las sesiones, observamos que Dani ante la lectura de un pequeño texto, empieza a mirar al techo, a moverse inquieto en la silla y verbaliza "no sé..., quiero dibujar...". Dado que interpretamos estas conductas como "defensivas", le decimos: 
"Ay, Dani, ¿sabes? Creo que ya sé lo que le pasa a Dani. ¿Sabes la historia de Pipo? (niega gestualmente) Pues, ¿quieres que te la cuente? (ahora se tranquiliza, mira y afirma gestualmente). Pues mira, Dani, había una vez un extraterrestre que se llamaba Pipo que aterrizó en un parque. Bajó de su nave y se encontró con Toni, un niño que estaba jugando. Toni al principio tenía un poco de reparo al verlo pero se percató de que Pipo sólo quería ser su amigo y empezó a jugar con él. Al cabo de un ratito, Pipo le dijo a Toni que estaba muy hambriento. Toni le invitó a su casa. Entraron en la cocina y Toni vio una olla con sopa que su madre había preparado. La calentó un poquito y sirvió un plato de la exquisita sopa a su amigo mientras iba preparando más comida. Pipo se sentó delante del plato de sopa, cogió un tenedor y empezó a comer la sopa. No sabía qué pasaba. Con lo hambriento que estaba y la sopa se le iba resbalando sin poder comérsela. Llamó a Toni y le dijo que era tonto, que no era capaz de comer la sopa, que lo veía muy difícil y que le diera otra cosa para comer. Toni le respondió: «Ay, Pipo, no, no..., ya sé qué pasa..., fijate...» Cogió una cuchara y se la dio a Pipo quién ahora sí que se comió toda la sopa en un periquete. Cuando hubo terminado le dijo a su amigo: «Toni, fijate, jsí que era capaz de comerme la sopa, el problema era que no tenía la cuchara!». (Después, le digo a Dani.) ¿Sabes qué pasa Dani? Que creo que ahora Dani también necesita una cuchara que le permita "comerse» este texto". (Dani sonríe, afirma gestualmente y empieza a leer el texto...).

\section{las expresiones verbales o}



\section{pueden constituir una evidencia}

\section{de que se desencadena un}

\section{proceso emocional previo al cognitivo que va a dificultarlo e incluso a impedirlo}

La metáfora de Pipo nos ha sido francamente útil para transmitir indirectamente a Dani el mensaje emocional "no es que no seas capaz sino que no sabes cómo hacerlo". Ya nos podemos imaginar cuál hubiera sido el resultado si en vez de contarle la metáfora, le hubiéramos dicho más o menos este mensaje de una manera lógica, intentando que lo entendiera y se convenciera. Seguro que no sólo no lo habríamos logrado, sino que también habríamos reforzado las conductas defensivas. Además, a partir de ahora, sin necesidad de repetir la metáfora, podemos usar el "ancla" de la "cuchara" para ayudar a Dani a vivir experiencias emocionales de signo opuesto a las que había vivido anteriormente. Es decir, cuando observemos conductas defensivas ante cualquier tarea, le podemos decir algo así como: "Creo que Dani necesita encontrar la cuchara... ¿Quiere Dani que le ayude a encontrarla?".

Obviamente la empatía entre el educador y Dani es imprescindible pues en caso contrario, la amígdala de Dani percibirá como "peligrosa" nuestra relación con él y va a actuar defensivamente hagamos lo que hagamos. La empatía es la llave que nos permite abrir la puerta de los procesos emocionales. Sin ella, el perro guardián que todos llevamos dentro considera que quien se acerca a la puerta es un intruso y va a hacer todo lo que pueda para que no entre. Un grito, una mirada que exprese dureza, un comentario despectivo pueden "despertar" al perro guardián. Todo un reto para los profesionales de la educación.

\section{Para saber más}

- LeDoux, J. (1999). El cerebro emocional. Barcelona: Editorial Planeta SA.

- LURIA A. R. (1980). Higher cortical functions in man ( $2^{a}$ ed.). New York: Basic Books.

- Timoneda, C. (1999). "Cognición, emoción y conducta: modelo humanista-estratégico: Una propuesta de diagnóstico e intervención psicopedagógica basada en y desde la práctica". Revista de investigación educativa, 17 (2), pp. 515-520.

- Timoneda C. (2011). "Case report: Elegant and Hasty". The Milton Erickson Foundation Newsletter, 3I (2), pp. II-12. http://www.erickson-founda tion.org/ipages/newsletterpdfs/Vol-3I-No-2.pdf

- Timoneda Gallart, C., y Pérez Álvarez, F. (2012). "Neuropsicopedagogia de la Dislexia: un Enfoque Innovador para su Diagnóstico y Tratamiento". Revista Electrónica de Dificultades de Aprendizaje, 2 (I), pp. I-27.

- www.fcarmevidal.com Web de la Fundació Carme Vidal Xifre de Neuropsicopedagogia. En el apartado Publicaciones están disponibles diferentes artículos, ponencias y trabajos de investigación y/o divulgación relativos al tema. 